\title{
Radar and satellite investigations of equatorial evening vertical drifts and spread $F$
}

\author{
J. M. Smith ${ }^{1}$, F. S. Rodrigues ${ }^{1}$, and E. R. de Paula ${ }^{2}$ \\ ${ }^{1}$ William B. Hanson Center for Space Sciences, The University of Texas at Dallas, Richardson, TX, USA \\ ${ }^{2}$ Instituto Nacional de Pesquisas Espaciais - INPE, São José dos Campos, SP, Brazil
}

Correspondence to: J. M. Smith (jms106020@utdallas.edu) and F. S. Rodrigues (fabiano@utdallas.edu)

Received: 24 August 2015 - Revised: 12 October 2015 - Accepted: 22 October 2015 - Published: 11 November 2015

\begin{abstract}
We analyzed pre-midnight equatorial F region observations made by the $30 \mathrm{MHz}$ coherent backscatter radar of São Luis, Brazil between August 2010 and February 2012. These measurements were processed, and used to create monthly maps of the echo occurrence as a function of local time and height. The maps show the inter-annual variability associated with equatorial spread $F$ (ESF) occurrence in the Brazilian longitude sector. We also constructed monthly curves of the evening vertical drifts, for the Brazilian sector, using measurements by the ion velocity meter (IVM) onboard the C/NOFS satellite. The IVM evening drifts show a good overall agreement with the Scherliess and Fejer (1999) empirical model. Measured and model drifts show the development of the pre-reversal enhancement (PRE) of the vertical plasma drifts during ESF season. Using joint radar and satellite measurements, we found that evening (18:00-18:30 LT) mean non-negative drifts provide a necessary but not sufficient condition for the occurrence of topside ESF echoes. Evening downward (negative) drifts preceded the absence of topside ESF irregularities.
\end{abstract}

Keywords. Ionosphere (electric fields and currents; equatorial ionosphere; ionospheric irregularities)

\section{Introduction}

Equatorial spread $F$ (ESF) is the general name given to signatures of a broad spectrum of field-aligned electron density irregularities, which are commonly observed in the lowlatitude $\mathrm{F}$ region ionosphere after sunset hours (e.g. Fejer and Kelley, 1980).

First, large scale-size (tens of $\mathrm{km}$ ) ionospheric perturbations develop as a result of a primary plasma instability.
Then, secondary plasma instabilities drive the generation of smaller scale irregularities on the walls (or within) the primary, large-scale electron density perturbations (e.g. Saito et al., 1998; Hysell et al., 2009). Ionospheric irregularities with scale sizes as short as a few $\mathrm{cm}$ have been observed during ESF (Woodman, 2009). ESF irregularities are, in general, first observed in the bottomside equatorial $\mathrm{F}$ region, then develop vertically reaching altitudes that can exceed $1000 \mathrm{~km}$.

We currently seek a better understanding of the underlying physical processes leading to the generation and variability of ESF. The study of ESF is also motivated by the impact small-scale (few hundreds of meters) ionospheric irregularities have on the propagation of radio waves. ESF irregularities can produce drastic changes in the index of refraction of ionospheric medium, which cause the diffraction of radio waves such as those used by satellite-based communication and navigation systems (Kintner et al., 2007).

The occurrence of the large-scale size ESF irregularities are often attributed to the so-called Generalized RayleighTaylor (GRT) plasma instability. An expression describing the local linear growth rate of the GRT instability is given by (B. Basu, 2002):

$\gamma=\left[\frac{E_{z}}{B}+\frac{g}{v_{\text {in }}}+\frac{v_{\text {in }}}{\Omega_{i}} U_{z}-U_{v}\right] \frac{1}{L}$

where $L=\left(\frac{1}{n} \frac{\mathrm{d} n}{\mathrm{~d} h}\right)^{-1}$ is the electron density vertical scale length, $g$ is the acceleration due to gravity, $\nu_{\text {in }}$ is the ionneutral collision frequency, $\frac{E_{z}}{B}$ is the vertical component of the $\boldsymbol{E} \times \boldsymbol{B}$ plasma drift, and $U_{z}$ and $U_{v}$ are the zonal and vertical components of the thermospheric neutral wind velocity, respectively. A more complete formulation for the growth rate takes into account flux-tube integrated quantities (Sultan, 1996). Notice that the growth rate is scale-size independent. 
Therefore, it is expected that the scale size of the primary structures will be dictated by the scale size of the initial perturbation triggering (or seeding) the instability.

The pre-reversal enhancement (PRE) of the equatorial zonal electric field that occurs around sunset hours contributes directly and indirectly to the linear growth of the GRT instability. The PRE produces large values of the upward $\left(E_{z} / B\right)$ plasma drifts. It also lifts up the ionospheric plasma to altitudes where $v_{\text {in }}$ is significantly reduced. Theoretical and numerical analysis of the GRT instability indicate that the linear growth rate maximizes in the equatorial bottomside $\mathrm{F}$ region around sunset hours, which is in good agreement with ESF observations (e.g. Fejer et al., 1999; Retterer and Gentile, 2009). Quiet-time ESF has been observed to occur, mainly, after sunset and last until approximately local midnight (Hysell and Burcham, 1998; Kil and Heelis, 1998; Abdu et al., 2000). There have been reports, however, of ESF events occurring around local midnight and even later at night during low solar flux conditions (e.g. Yokoyama et al., 2011; Candido et al., 2011; Nishioka et al., 2012).

A number of studies have suggested that the magnitude of the PRE dictates the development of ESF (e.g. Fejer et al., 1999; Abdu, 2001; Retterer and Gentile, 2009; Huang and Hairston, 2015). Here, we present results of further analyses of the relationship between the evening vertical plasma drifts and ESF on a monthly and case-by-case (daily) basis. We focus, in particular, on combining observations of drifts made by satellite sensors over the Brazilian longitude sector $\left(\sim 45^{\circ} \mathrm{W}\right)$ and the relation of these drifts to ESF measured by a ground-based radar. Such a study is timely given the upcoming satellite missions (ICON and COSMIC-2) equipped with sensors capable of measuring ionospheric plasma drifts.

This report is organized as follows: Sect. 2 provides a quick description of the $30 \mathrm{MHz}$ São Luis radar and the F region mode used for ESF measurements. We also provide details about the Scherliess and Fejer (1999) model used to obtain climatological estimates of the $\mathrm{F}$ region drifts over the Brazilian sector. Section 2 also provides details on the in situ satellite measurements made by the C/NOFS satellite and used in our study of the relationship between PRE and ESF. In Sect. 3, we describe our analysis of the measurements. The results of our analysis are presented and discussed in Sect. 4. Our findings and conclusions are summarized in Sect. 5.

\section{Measurements and models}

\subsection{Equatorial spread $F$}

Measurements of ESF ionospheric irregularities in the Brazilian sector were made using a $30 \mathrm{MHz}$ coherent backscatter radar installed in the equatorial site of São Luis $\left(2.59^{\circ} \mathrm{S}, 44.21^{\circ} \mathrm{W},-2.66^{\circ}\right.$ dip latitude). The radar probes $5 \mathrm{~m}$ electron density irregularities with scale sizes matching the Bragg scattering condition.
The São Luis radar is a low-power radar system that has been used for studies of equatorial ionospheric irregularities in the E and F regions (de Paula and Hysell, 2004; Rodrigues et al., 2004, 2008, 2011; Shume et al., 2011). The radar is equipped with four independent antenna sets connected to four receivers. Each antenna set is formed by an array of $4 \times 4$ Yagi antennas. The arrays have been placed non-uniformly in the magnetic zonal direction for radar imaging studies of scattering layers. Two $4 \mathrm{~kW}$ transmitters are available for observations and are normally used for $\mathrm{F}$ region measurements. For this study, we only used measurements from antenna arrays 1 and 2 , which are spaced by $2.5 \lambda$, where $\lambda$ is the wavelength of the radar signal $(10 \mathrm{~m})$. Arrays 1 and 2 are used for both transmission and reception. Each $4 \mathrm{~kW}$ transmitter is connected to an array.

Even though the São Luis radar has been making measurements since 2000 , only observations made between July 2010 and February 2012 are used for this study. The measurements were obtained after an upgrade in the data acquisition system of the radar, which allowed the observations to be processed more quickly than previously possible. The radar stopped generating usable measurements in February 2012 after a series of technical issues.

For $\mathrm{F}$ region measurements, we used 28-bit coded pulses, with a $9.33 \mathrm{~ms}$ inter-pulse period (IPP). The baud length and sampling were $2.5 \mathrm{~km}$. A total of 250 samples were collected per IPP. No coherent integration was performed in order to be able to estimate Doppler velocities between -270 and $+270 \mathrm{~m} \mathrm{~s}^{-1}$ without spectral aliasing effects. This study, however, only utilizes echo signal-to-noise (SNR) estimates. This observation setup allowed us to make measurements of the $\mathrm{F}$ region from 200 to $825 \mathrm{~km}$ altitude with a range resolution of $2.5 \mathrm{~km}$.

\subsection{Equatorial plasma drifts}

To understand the variability of ESF in the Brazilian sector, we analyzed in situ measurements of vertical plasma drifts made by the Ion Velocity Meter (IVM) instrument onboard the Communication/Navigation Outage Forecasting System (C/NOFS) satellite. C/NOFS IVM measurements of drifts were available for the period when São Luis made ESF measurements.

The C/NOFS satellite is a low inclination orbit $\left(13^{\circ}\right)$ satellite with perigree at around $400 \mathrm{~km}$ and apogee at approximately $800 \mathrm{~km}$. It has a precession period of approximately 67 days, which means that it takes about 67 days to make measurements at all local times for a given longitude and altitude. C/NOFS was launched in April 2008 and operated nearly continuously until July 2013. The satellite was equipped with several sensors for study of the low-latitude ionosphere with particular emphasis on ESF. The main objective of the C/NOFS mission was to advance our understanding and our ability to nowcast and forecast ESF irregu- 
larities and their effects on radio-based communication and navigation systems (de La Beaujardière et al., 2004).

The IVM instrument is part of NASA's Coupled IonNeutral Dynamics Investigation (CINDI) package. It is formed by a Retarding Potential Analyzer (RPA) and an Ion Drift Meter (IDM). The RPA is responsible for measurements of the ion composition, temperature and velocity in the ram direction. The IDM is responsible for measurements of the ion velocity in two orthogonal directions in the plane transverse to the satellite velocity. The IVM measurements were processed and made available to this study by the CINDI team. Three-dimensional vectors of the drift velocity were provided in geomagnetic coordinates. In this coordinate system, the first vector component is aligned with the geomagnetic field vector, the second component is in the geomagnetic eastward direction, and the last component is in the magnetic meridional (vertical at the equator) direction. Initially, IVM vector velocities were provided every $0.5 \mathrm{~s}$. Changes in the analyses of the RPA measurements, however, caused the vector velocities to be provided every $1 \mathrm{~s}$, starting on 29 July 2010.

In addition to C/NOFS IVM drifts, we also used predictions of the equatorial vertical plasma drifts made by the empirical climatological model developed by Scherliess and Fejer (1999) (SF99) to better understand the variability of ESF in the Brazilian sector. A comparison of the model and measured drifts also allows us to confirm the adequacy of our selection criteria for the IVM observations representing equatorial drifts. The SF99 model was developed using $F$ region drift measurements made by the Jicamarca incoherent scatter radar (ISR) located near Lima, Peru $\left(11.95^{\circ} \mathrm{S}\right.$, $\left.76.87^{\circ} \mathrm{W}\right)$. Approximately 500 days of ISR measurements made between 1968 and 1992 were used in the model development. To extend the model to other longitude sectors, in situ measurements made by an IDM onboard the Atmospheric Explorer E (AE-E) satellite were also used. The AEE satellite was in a low inclination $\left(19.76^{\circ}\right)$ orbit and operated between 1975 and 1981. For the development of the model only measurements made between January 1977 and December 1979 were used. During that time, the satellite was in a nearly circular orbit at an altitude that varied from 230 to $470 \mathrm{~km}$. The empirical model is based on cubic B-splines of order four and describes the mean $\mathrm{F}$ region vertical plasma drifts as a function of geographic longitude, local time, day of the year, and daily solar flux. The longitudinal and temporal resolution of the model is $30^{\circ}$ and $30 \mathrm{~min}$, respectively. The Scherliess and Fejer (1999) model is the most widely used model of equatorial vertical drifts. It is often used as a reference for vertical drifts, and input of ionospheric models for studies of the equatorial and low-latitude ionosphere.

\section{Analysis}

\subsection{Radar measurements}

After each observation day, the raw voltages measured by the São Luis radar were analyzed in a procedure similar to that used by the Jicamarca Unattended Long-term Investigations of the Ionosphere and Atmosphere (JULIA) mode of the Jicamarca radar Hysell and Burcham (1998). The normalized complex cross-correlation of the voltages measured by antenna sets 1 and 2 was computed for each range gate. The cross-correlation function allows us to estimate the coherency and phase difference of the backscattered signals measured by the spaced antennas. These parameters are used to identify localized scatterers and estimate the mean zonal velocity of the irregularities within the volume illuminated by the radar (Farley et al., 1981; Kudeki et al., 1981).

The zero and first $(\tau=9.33 \mathrm{~ms})$ lags of the autocorrelation function (ACF) of the signals measured by antennas 1 and 2 were also computed. The ACF allow us to estimate the SNR of echoes observed by the radar and the line-of-sight (upward) Doppler velocity of the irregularities responsible for the echoes. For this study, we focus on the SNR estimates of the echoes observed during geomagnetically quiet conditions. We define our criteria for geomagnetic conditions in the following section.

Figure 1 shows examples of echoes observed by the São Luis radar. It shows range-time-intensity (RTI) maps of echoes observed on three different days. The top panel shows the detection of a weak (based on echo intensity), smooth echoing region that did not develop in altitude. The middle panel shows a more structured, stronger echoing region. Finally, the bottom panel shows a very strong echoing layer that develops well in altitude reaching typical topside heights. The top, middle and bottom panels show examples of bottom-type, bottomside and topside RTI echoing layers first described by Woodman and LaHoz (1976) based on early radar measurements made at Jicamarca.

The geomagnetic activity conditions of the radar measurements were evaluated using the Planetary K (Kp) index. For each measurement (estimate of SNR), we identified the $\mathrm{Kp}$ index of the $3 \mathrm{~h}$ interval that the measurement falls within and the previous 3 values of $\mathrm{Kp}$. In the analysis for this study, we only considered measurements where none of the four $\mathrm{Kp}$ indices exceeded 3 . Therefore, we limited our observations to those made during geomagnetic conditions considered quiet.

\subsection{C/NOFS IVM measurements}

To help our understanding of the morphology of ESF events observed by the São Luis radar and their relationship with the PRE, we constructed monthly average curves of the equatorial vertical drifts over São Luis. The curves were obtained by carefully selecting C/NOFS IVM measurements of meridional drifts made when the satellite was passing at magnetic 

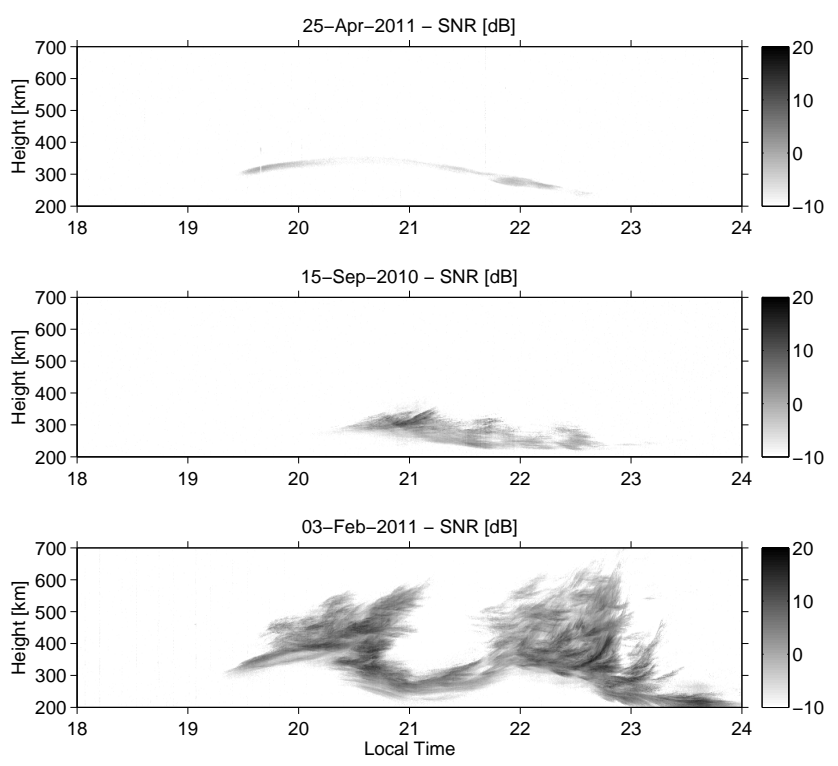

Figure 1. Examples of measurements made by the São Luis radar and used in this study. The three panels show the range-timeintensity (RTI) maps of F region echoes observed on three different days. The top, middle and bottom panels show the occurrence of bottom-type, bottomside and topside equatorial spread $F$ events, respectively.

field lines whose apex longitudes were within $15^{\circ}$ magnetic longitude of the site. We also only used measurements made near the magnetic equator, that is, where the magnitude of the magnetic inclination was less than $15^{\circ}$. To avoid measurements with larger uncertainties, we only selected observations made below $600 \mathrm{~km}$ altitude where the ionospheric plasma is formed, mostly, by atomic oxygen ions.

In order to minimize the effects of electric fields of magnetospheric origin we only used measurements made during periods considered geomagnetically quiet. Similar to what was done with the radar measurements, we evaluated the Kp index for each measurement made by the IVM. Again, we ensured that the measurements used in our analyses were made during geomagnetically quiet conditions by selecting only observations made when the Kp index (and the three previous $\mathrm{Kp}$ values) was below 3. Finally, we limited our analysis of the IVM measurements to observations made in the 17:00-20:00 LT range, which is around the expected time ( 19:00 LT) of occurrence of the PRE of the zonal equatorial electric field Scherliess and Fejer (1999).

\section{Results and discussion}

\subsection{Mean vertical drifts}

Figure 2 shows results of our analysis of the vertical drift measurements made by the IVM near the São Luis site. The figure shows monthly averages of the drifts that match our se- lection criteria (Sect. 3.2). The black markers in Fig. 2 show the mean values of the drifts. The red markers show the median. The median is calculated to identify the occurrence of any obvious asymmetric (with respect to the mean) distribution of drift values. The mean and median values are usually very close, which indicates the absence of outliers or abnormal measurements. The error bars represent the standard deviation of the data used in the averages. The vertical green bars show the number of observations (divided by 10) for each time bin ( $15 \mathrm{~min}$ intervals). The lack of abrupt changes from one average drift value to the next reinforces the good quality of the measurements. We did not apply any running average nor used common data points for consecutive data bins. Gaps indicate times when less than 75 measurements per time bin were available.

The results in Fig. 2 show that between September and April, mostly positive (upward) drifts are observed between 17:00 and 20:00 LT. During those months, despite the reduced number of points compared to previous climatological studies (Scherliess and Fejer, 1999; Fejer et al., 2008; Kil et al., 2009), it is still possible to identify the PRE of evening vertical drifts between 18:30 and 19:00 LT. The results also show that the average vertical drifts are mostly downward in May, June, July and August between 17:00 and 20:00 LT. Previous observations and theoretical analyses show that drifts should be predominantly upward between 17:00 and 20:00 LT (e.g. Scherliess and Fejer, 1999; Fesen et al., 2000). Stoneback et al. (2011), however, analyzed C/NOFS IVM measurements made between 2008 and 2010 and found large downward average drifts in the afternoon (16:00-18:00 LT) in all longitude sectors and seasons. They associated the occurrence of negative drifts in the afternoon and upward drifts around midnight to an enhancement of the semi-diurnal components of tidal winds at low-latitudes during the 2008-2009 extreme solar minimum. The magnitude of our downward drifts are not as large as those obtained by Stoneback et al. (2011). This can be, at least in part, because we limited our analysis to CINDI measurements made near the magnetic equator (within $\pm 15^{\circ} \mathrm{mag}$. inclination) and because our measurements were made during higher solar flux conditions than those examined by Stoneback et al. (2011). We also only detected predominant negative drifts around June solstice while Stoneback et al. (2011) observed downward drifts in all seasons. They did point out, however, that the semi-diurnal component of the drifts was strongest during solstices.

Figure 2 also shows the effects of the varying solar flux activity on the magnitude of the PRE. The PRE peak is severely reduced during periods of lower F10.7. There are a few cases when measurements for the same month, but different year and solar flux conditions, are available. This is the case of July 2010/2011, September 2010/2011, February 2011/2012, March 2011/2012, April 2011/2012 and June 2011/2012. When comparing the measurements made during those months, one can see that the PRE peak clearly 

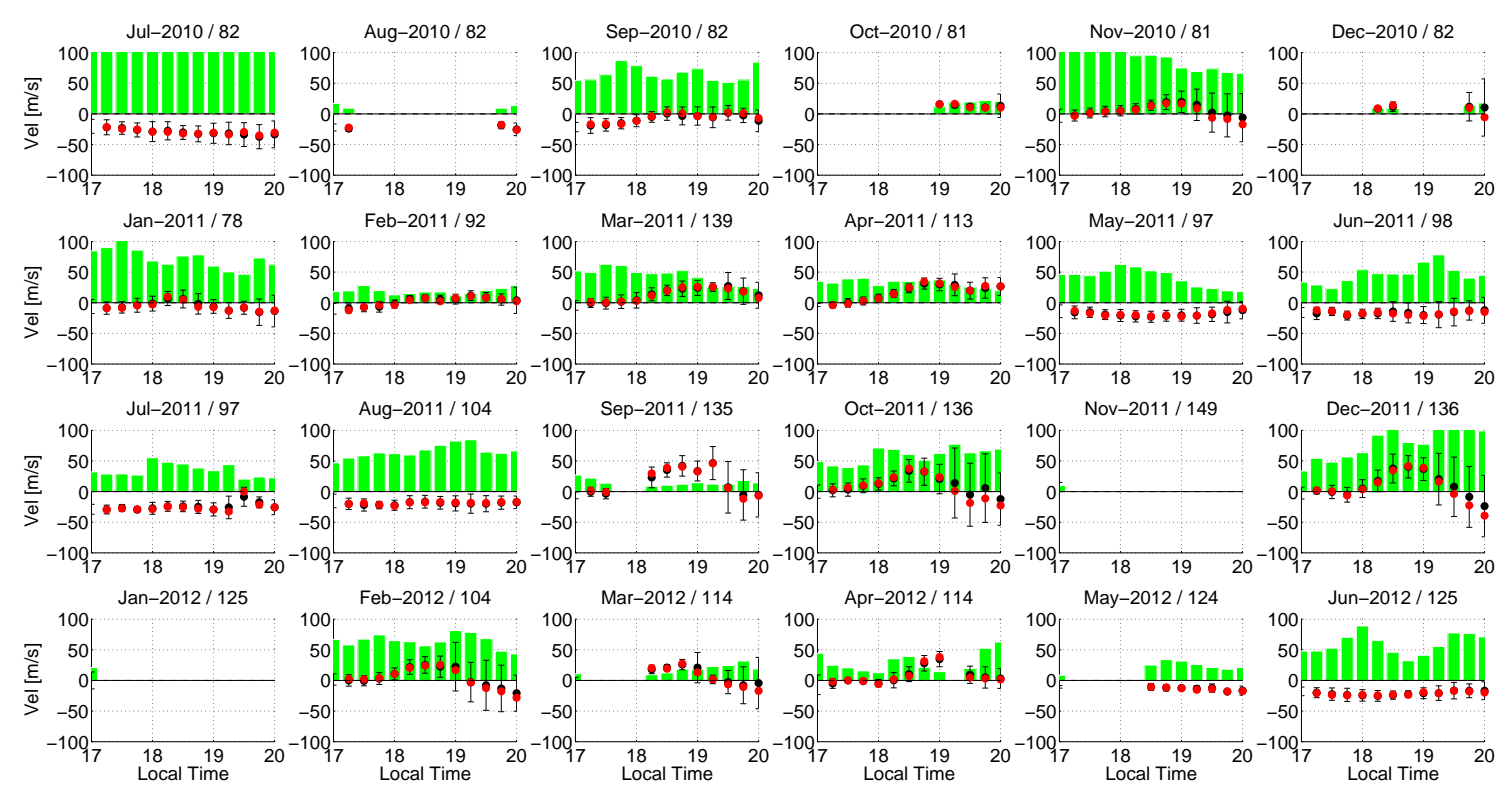

Figure 2. Monthly averages of quiet-time vertical plasma drift measured by C/NOFS near the São Luis site. The green bars indicate the number of measurements available (divided by 10) for each 15 min time bin. The black and red markers are results of regular arithmetic mean and median, respectively. The error bars represent the standard deviation of the drifts.

increases with F10.7. This is a result of the increase, with solar flux, of thermospheric zonal wind velocities and ratio of the $\mathrm{F}$ to $\mathrm{E}$ region magnetic flux tube integrated conductivities (e.g. Fejer et al., 1991). The drifts did not change much for the months of June and July at least for the period analyzed here.

The standard deviation (error bars) in the average curves already indicates a close relationship between vertical drifts and ESF. During months when the drifts are mostly negative, the errorbars (variability) of the drifts remain low, below approximately $10 \mathrm{~m} \mathrm{~s}^{-1}$. During months when the PRE peak occurs, the errorbars after 19:00 LT increase substantially. This increase in the variability of the drifts is indicative of large, turbulent flows associated with polarization electric fields within ESF plasma depletions.

\subsection{Mean ESF occurrence rate}

Figure 3 presents the monthly maps of the occurrence of ESF as a function of local time and height. The color maps in each panel show the occurrence rate of irregularities (causing echoes with SNR $>0 \mathrm{~dB}$ ) each month between July 2010 and July 2012. Only measurements made during quiet-time geomagnetic conditions were taken into account when creating the occurrence rate maps. Above each panel, we indicate month and year, the mean solar flux index (F10.7 in SFU) for that month, and the number of evenings with observations made on that month. Unfortunately, during some months only a few nights (or none) of measurements were available. Blank panels indicate months when less than five evenings of observations were available. Despite the lack of measure- ments during some months, we can still identify a great deal of inter-annual variability in the occurrence of ESF irregularities causing radar echoes.

The most striking feature in the occurrence rate maps is the lack of echoes between April and August. Again, this is in good agreement with previous studies of ESF in the Brazilian longitude sector. These are months of minimal occurrence of ESF irregularities as observed by ionosondes or optical (airglow) instruments (e.g. Abdu, 2001; Sobral et al., 2002). de Paula et al. (2011) analyzed RTI maps of São Luis radar echoes observed between 2001 and 2008, and also found that only a few cases of bottomside and bottom-type echoes were observed during June solstice. Topside echoes, which are associated with ionospheric plasma bubbles occurred, predominantly, between September and March. Our maps also show that the occurrence of echoes, in the topside (say above $400 \mathrm{~km}$ altitude) increase with solar flux. Additionally, the maps also show that the lowest altitude of the echoes increases with solar activity. These are features that have already been found in previous experimental studies (e.g. Chapagain et al., 2009; de Paula et al., 2011). Numerical simulations of the nonlinear evolution of ESF instabilities indicate that the plasma depletions stop rising when the magnetic flux-tube integrated ion mass density inside the depletion matches the value of the surrounding background plasma (e.g. Krall et al., 2010). Therefore, radar observations indicate that the height at which the matching condition occurs increases with solar flux. The bottomside $\mathrm{F}$ region is lifted to higher altitudes during high solar flux conditions, which explains the altitude of the first echoes to increase with solar flux. 

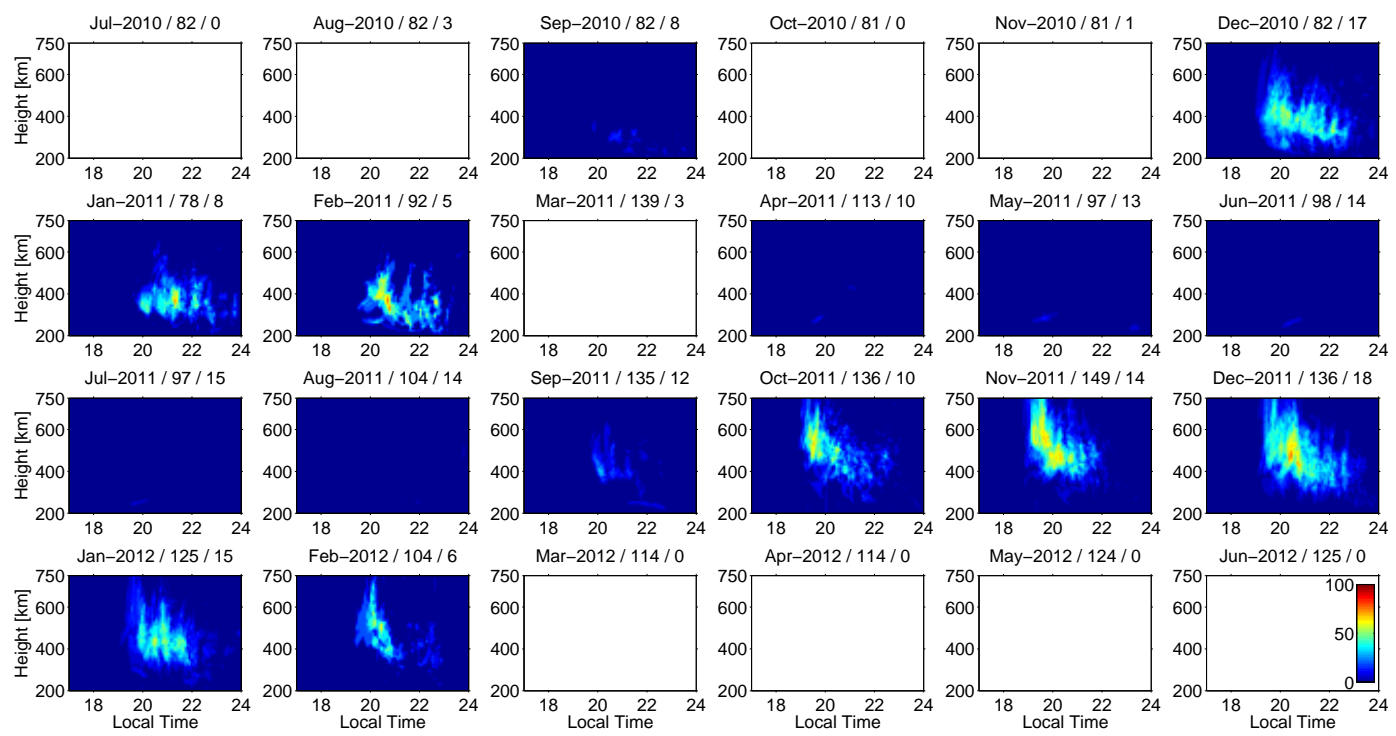

Figure 3. Monthly occurrence of F region echoes (SNR $>0 \mathrm{~dB}$ ) observed by the São Luis radar. Blank panels indicate months when ESF measurements were not made (radar did not operate) or less than five nights of observations were available.

\subsection{PRE and ESF}

\subsubsection{Monthly variability}

In order to better understand the observed ESF occurrence and its relation to the PRE, we show the mean $F$ region drifts (markers plus errorbars) calculated using IVM measurements superimposed on ESF occurrence maps in Fig. 4. The horizontal dashed lines indicate $-50,0$ and $+50 \mathrm{~m} \mathrm{~s}^{-1}$ vertical drift values. In addition to mean measured drifts, we also show the F region drifts predicted by the SF99 model for São Luis (solid line).

There is a general good agreement between IVM estimates of the drifts and the SF99 predictions, despite the limited number of IVM measurements used in our averages and the limited number of AE-E observations used to expand the SF99 model to longitudes outside the Jicamarca sector. This is particularly true for months when ESF is observed. During non-ESF months (May, June, July and August), however, one can observe a noticeable discrepancy between the measurements and model predictions. As mentioned earlier, unexpected downward drifts were observed by C/NOFS around June solstice.

Given the previous studies indicating that the PRE is the most important parameter controlling the occurrence of ESF (e.g. Fejer et al., 1999; Abdu, 2001; Su et al., 2008), one would expect ESF occurrence rates to be modulated by changes in the average PRE. Figure 4 does show that ESF is more likely to be observed during months when the average PRE peak develops even with a small amplitude. More surprisingly, perhaps, Fig. 4 shows that the ESF occurrence rate can be very small despite a significant mean PRE peak. This is the case of April and September 2011. Furthermore, we found months when the average PRE peak is small (but positive) and the ESF occurrence rate is significant ( $>50 \%$ for some heights and local times). This is the case of January and February 2011.

These discrepancies between monthly values of the PRE and ESF indicate that factors other than vertical drifts, which control the linear development of the GRT instability (Eq. 1) can help shape the ESF climatology in the Brazilian sector. These factors include zonal and vertical neutral winds, weak bottomside density gradients, and large ion-neutral collision frequencies. Off-equatorial E-region conductivities can also affect the field-line integrated linear growth rate Sultan (1996). Previous studies have also suggested that initial density perturbations (seed waves) could play a significant role in the development of ESF (e.g. Abdu et al., 2009; Kherani et al., 2009; Tsunoda, 2010). The low ESF occurrence despite a significant PRE could be attributed to the absence of triggering perturbations. The occurrence of ESF despite weak PRE could be associated with more effective (larger amplitude) initial perturbations. Recent studies have also suggested that ESF development is associated with the collisional shear instability (CSI) whose main driver is the retrograde plasma motion (with respect to neutrals) in the bottomside F region (Hysell and Kudeki, 2004; Kudeki et al., 2007). The low ESF occurrence would then be caused by conditions that are unfavorable to CSI growth. We must also point out that ESF development can also be affected by the temporal variation of geophysical parameters, including drifts, which control the non-linear evolution of interchange instabilities.

Finally, discrepancies between PRE and ESF occurrence could be due, at least in part, to the non-concurrency of the satellite and radar observations. In other words, it is pos- 

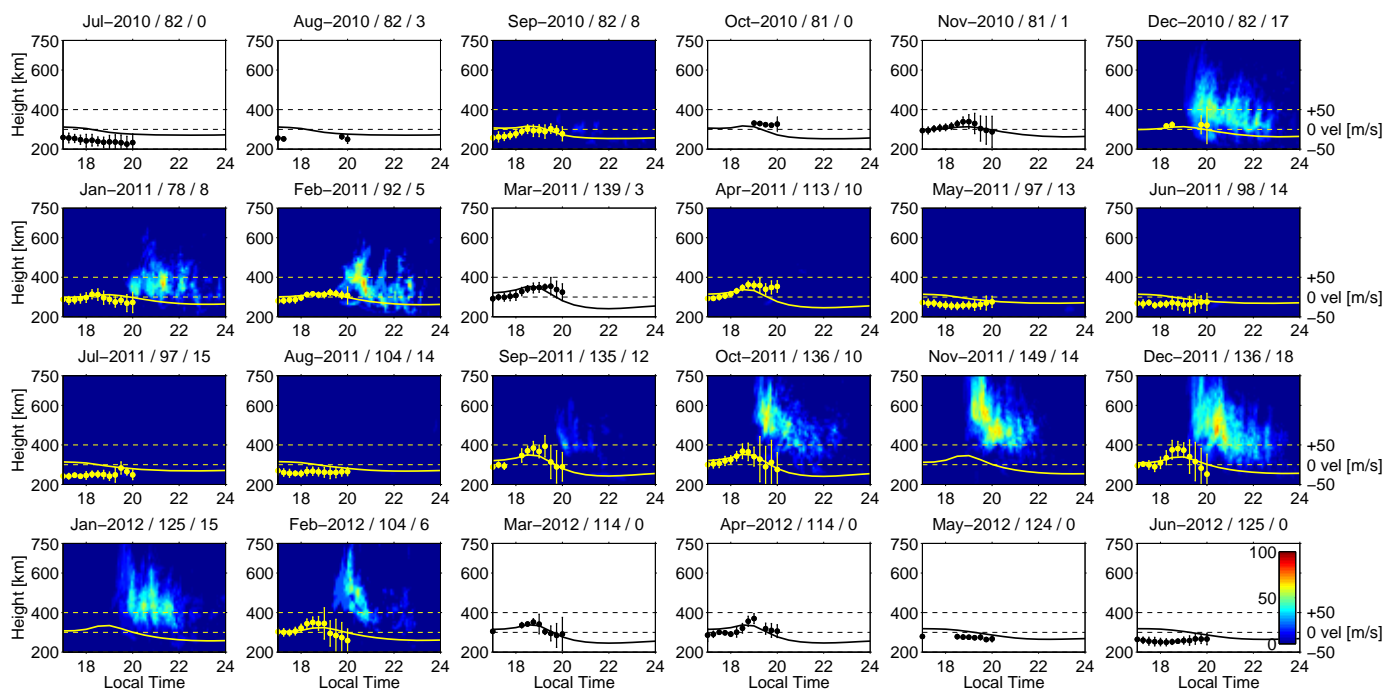

Figure 4. Monthly occurrence of F region echoes observed by the São Luis radar. Blank panels indicate months when ESF measurements were not made (radar did not operate) or less than five nights of observations were available. Mean F region vertical drifts are also shown for each month. Measured drifts are shown as markers. Model drifts are shown as solid lines. The dashed lines indicate $-50,0$, and $-50 \mathrm{~m} \mathrm{~s}{ }^{-1}$ drifts.

sible that the drift averages from the satellite passes contain mostly days of significant PRE, and ESF measurements were mostly made on different days without PRE. We explore this hypothesis and the day-to-day correlation between the evening drifts and ESF by focusing on nearly collocated, same-day observations. The results are discussed in the following section.

\subsubsection{Day-to-day variability}

In addition to investigating the correlation between in situ vertical drifts and ground-based detection of ESF structures on a monthly basis, we also investigated the correlation between drifts and ESF on a day-to-day basis. For that purpose, we only used measurements made by the São Luis radar, when the C/NOFS satellite flew over the São Luis sector, within $\pm 15^{\circ}$ apex longitude from the radar site, and $\pm 15^{\circ}$ magnetic inclination from the magnetic equator. In particular, we looked into passes occurring within \pm 15 min of four local times: 18:00, 18:30, 19:00 and 19:30 LT. For each day, we computed the occurrence rate of topside (above $400 \mathrm{~km}$ altitude and stronger than $0 \mathrm{~dB}$ ) echoes observed between 20:00 and 24:00 LT. For instance, an occurrence rate of 1 means that echoes were observed at all times, between 20:00 and 24:00 LT, above $400 \mathrm{~km}$ altitude. Conversely, an occurrence rate of 0 means that no echoes were observed between 20:00 and 24:00 LT and above $400 \mathrm{~km}$ altitude. These criteria ensure a more direct and quantitative comparison between the PRE peak and the occurrence of well-developed (topside) ESF structures.
The results of our analysis are presented in Fig. 5, which shows the scatter plot of the mean vertical drifts versus topside echo occurrence rate. Scatter plots are shown for vertical drifts measured within the four different local time windows. The horizontal bars represent the standard deviation of the drift values used to compute the averages. Figure 5 shows that negative mean drifts are good precursors of the absence of topside ESF. Topside structures were not observed for cases of negative drifts occurring around 18:00 or 18:30 LT. The results also show that a positive mean drift value around 18:00 or 18:30 LT is a necessary, but not sufficient condition for the development of topside ESF. We found, for instance, a case where the mean vertical drift was about $32 \mathrm{~m} \mathrm{~s}^{-1}$ at 18:30 LT and topside echoes were not observed. Mean drifts around 19:00 and 19:30 LT are not good indicators of ESF development or suppression. During that time, turbulent flows associated with ESF already seem to exist, and a large variability in the drifts is observed. This variability is evident in large error bars.

Previous studies suggest that a PRE peak reaching a certain "threshold" value is a necessary condition for fully developed ESF events to be observed (e.g. Basu et al., 1996; Fejer et al., 1999; Abdu et al., 2000). Reported values range from 10 to $50 \mathrm{~m} \mathrm{~s}^{-1}$. Fejer et al. (1999), however, pointed out that this threshold value can vary with solar flux. Our results, however, indicate that the threshold drift value, if one can be set, is approximately $0 \mathrm{~m} \mathrm{~s}^{-1}$ for the low-to-moderate solar flux conditions under which our measurements were made. This value is, at least in part, dictated by the averaging of the drift values measured during the passing of satellite over the São Luis sector. This averaging can reduce the threshold drift value. More recently, Huang and Hairston (2015) used in situ 

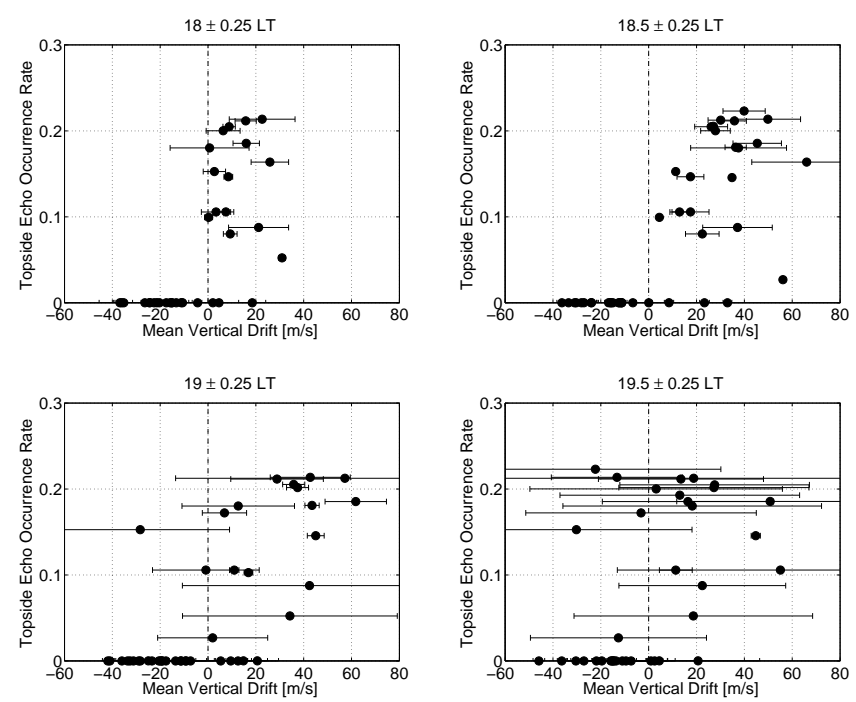

Figure 5. Scatter plots of the mean vertical drifts measured by the C/NOFS IVM near the São Luis site (at four different local times) versus the topside ( $>400 \mathrm{~km}$ altitude) echo occurrence rate during pre-midnight hours (20:00-24:00 LT) as measured by the São Luis radar on the same evening. The topside echo occurrence rate is defined as the number of height/LT bins in the RTI map between 20:00-24:00 LT and above $400 \mathrm{~km}$ altitude with SNR $>0 \mathrm{~dB}$ echoes divided by the total number of observations.

density and drift measurements made by the C/NOFS satellite to investigate the relationship between the PRE and ESF events detected above the satellite perigee $(\sim 400 \mathrm{~km})$. They also found that ESF is unlikely to occur for cases when the PRE is below $0 \mathrm{~m} \mathrm{~s}^{-1}$. Furthermore, their analyses show that ESF occurrence probably varies between 0 and $80 \%$ for PRE values between 0 and $40 \mathrm{~m} \mathrm{~s}^{-1}$, respectively. We also found that, despite a mean drift value between 0 and $40 \mathrm{~m} \mathrm{~s}^{-1}$, topside ESF echoes might not be observed. We only found a few cases of mean drifts exceeding $40 \mathrm{~m} \mathrm{~s}^{-1}$. Topside echoes were observed in all of those cases, which again is in agreement with the findings of Huang and Hairston (2015) stating that ESF is very likely to occur when PRE $>40 \mathrm{~m} \mathrm{~s}^{-1}$. Finally, we must point out that drifts are known to vary with height particularly during evening hours (Fejer et al., 2014). The height gradient of the drifts also has a large day-today variability. Therefore, a comparison between drifts obtained from ground-based instruments and satellite sensors is less than straightforward. Finally, the occurrence of topside ESF structures despite weak PRE peaks could also be associated with strong initial perturbations provided by atmospheric gravity waves as suggested by theoretical studies (e.g. Kherani et al., 2009).

\section{Conclusions}

We have analyzed observations of equatorial spread $F$ (ESF) events and evening plasma drifts made in the Brazilian longitude sector $\left(\sim 45^{\circ} \mathrm{W}\right)$. The ESF measurements were made by a $30 \mathrm{MHz}$ coherent backscatter radar while plasma drift observations were made by the IVM sensor on the C/NOFS satellite. Monthly-averaged curves of the evening IVM vertical drifts were in very good agreement with drift predictions by the Scherliess and Fejer (1999) model during most months. Some disagreement, however, was observed during June solstice (May-August) when measured drifts showed unexpected negative (downward) values in the late afternoon/evening hours.

To a first order, the inter-annual variability in the ESF occurrence correlated well with the peak magnitude of the pre-reversal enhancement (PRE) of the vertical drifts. ESF occurred when the mean PRE peak value was positive (upward). We found, however, months when the ESF occurrence rate was very small despite a significant $\left(\gtrsim 10 \mathrm{~m} \mathrm{~s}^{-1}\right)$ monthly-averaged PRE. We also found months when a significant ESF occurrence rate was observed despite a weak mean PRE peak. This indicates that the evening vertical drifts alone cannot fully explain ESF variability, and that other geophysical factors (e.g. winds, density gradients, seed waves) also contribute to shape the climatology of ESF in the Brazilian sector.

The lack of ESF despite a significant PRE could also be due, at least in part, to the non-concurrency of the radar and satellite observations, since drift and ESF measurements were not always made on the same days. To explore this hypothesis and to better quantify the day-to-day relationship between PRE and ESF, we combined nearly collocated ground- and space-based observations made on the same day. We found that, indeed, topside ESF events could develop even after weak evening drifts were observed. But we also found that negative (downward) mean drifts observed around 18:00 LT (or 18:30 LT) are indicators of ESF suppression. Topside echoes were not observed when the drifts were negative (downward). We must point out that positive drifts were not a sufficient condition for topside ESF events.

The C/NOFS mission is coming to an end and the São Luis coherent scatter radar stopped making observations in 2012. However, in the following years, a more comprehensive day-to-day analysis of the PRE and ESF relationship in the Brazilian sector can be done with upcoming satellite missions (e.g. ICON and COSMIC-2) as well as the recent deployment of a new coherent backscatter radar interferometer (MELISSA).

Acknowledgements. We would like to thank the technical support provided by the engineering staff of the São Luis Observatory. Ionospheric plasma drift measurements were made available by the UT Dallas CINDI team (http://cindispace.utdallas.edu). Work at UT Dallas was supported by AFOSR (FA9550-13-1-0095) and NSF 
(AGS-1261107).

The topical editor H. Kil thanks the two anonymous referees for help in evaluating this paper.

\section{References}

Abdu, M. A.: Outstanding problems in the equatorial ionospherethermosphere electrodynamics relevant to spread $\mathrm{F}, \mathrm{J}$. Atmos. Sol.-Terr. Phy., 63, 869-884, doi:10.1016/S13646826(00)00201-7, 2001.

Abdu, M. A., Sobral, J. H. A., and Batista, I. S.: Equatorial spread F statistics in the American longitudes: Some problems relevant to ESF description in the IRI scheme, Adv. Space Res., 25, 113124,2000

Abdu, M. A., Alam Kherani, E., Batista, I. S., de Paula, E. R., Fritts, D. C., and Sobral, J. H. A.: Gravity wave initiation of equatorial spread F/plasma bubble irregularities based on observational data from the SpreadFEx campaign, Ann. Geophys., 27, 2607-2622, doi:10.5194/angeo-27-2607-2009, 2009.

Basu, B.: On the linear theory of equatorial plasma instability: Comparison of different descriptions, J. Geophys. Res., 107, doi:10.1029/2001JA000317, 2002.

Basu, S., Kudeki, E., Basu, S., Valladares, C. E., Weber, E. J., Zengingonul, H. P., Bhattacharyya, S., Sheehan, R., Meriwether, J. W., Biondi, M. A., Kuenzler, H., and Espinoza, J.: Scintillations, plasma drifts, and neutral winds in the equatorial ionosphere after sunset, J. Geophys. Res.-Space, 101, 26795-26809, doi:10.1029/96JA00760, 1996.

Candido, C. M. N., Batista, I. S., Becker-Guedes, F., Abdu, M. A., Sobral, J. H. A., and Takahashi, H.: Spread F occurrence over a southern anomaly crest location in Brazil during June solstice of solar minimum activity, J. Geophys. Res.-Space, 116, a06316, doi:10.1029/2010JA016374, 2011.

Chapagain, N. P., Fejer, B. G., and Chau, J. L.: Climatology of postsunset equatorial spread F over Jicamarca, J. Geophys. Res.Space, 114, 2156-2202, a07307, doi:10.1029/2008JA013911, 2009.

de La Beaujardière and the C/NOFS Science Definition Team: C/NOFS: a mission to forecast scintillations, J. Atmos. Sol.-Terr. Phy., 66, 1573-1591, doi:10.1016/j.jastp.2004.07.030, 2004.

de Paula, E., Kherani, E. A., Cueva, R., and Camargo, L.: Observations of pre-midnight 5-m irregularities in the equatorial F region over São Luís, Brazil: Solar-flux dependence and seasonal variations, J. Atmos. Sol.-Terr. Phy., 73, 1544-1554, doi:10.1016/j.jastp.2011.03.014, 2011.

de Paula, E. R. and Hysell, D. L.: The São Luís $30 \mathrm{MHz}$ coherent scatter ionospheric radar: System description and initial results, Radio Sci., 39, RS1014, doi:10.1029/2003RS002914, 2004.

Farley, D. T., Ierkic, H. M., and Fejer, B. G.: Radar Interferometry: A New Technique for Studying Plasma Turbulence in the Ionosphere, J. Geophys. Res., 86, 1467-1472, 1981.

Fejer, B. G. and Kelley, M. C.: Ionospheric irregularities, Rev. Geophys., 18, 401-454, doi:10.1029/RG018i002p00401, 1980.

Fejer, B. G., de Paula, E. R., González, S. A., and Woodman, R. F.: Average vertical and zonal F region plasma drifts over Jicamarca, J. Geophys. Res.-Space, 96, 13901-13906, doi:10.1029/91JA01171, 1991
Fejer, B. G., Wensen, J. W., and Su, S.-Y.: Quiet time equatorial $F$ region vertical plasma drift model derived from ROCSAT-1 observations, J. Geophys. Res., 113, A05304, doi:10.1029/2007JA012801, 2008.

Fejer, B. G., Hui, D., Chau, J. L., and Kudeki, E.: Altitudinal dependence of evening equatorial $\mathrm{F}$ region vertical plasma drifts, J. Geophys. Res.-Space, 119, 5877-5890, doi:10.1002/2014JA019949, 2014.

Fejer, B. G., Scherliess, L., and de Paula, E. R.: Effects of the vertical plasma drift velocity on the generation and evolution of equatorial spread F, J. Geophys. Res., 104, 19859-19869, doi:10.1029/1999JA900271, 1999.

Fesen, C. G., Crowley, G., Robl, R. G., Richmond, A. D., and Fejer, B. G.: Simulation of the pre-reversal enhancement in the low latitude vertical ion drifts, Geophys. Res. Lett., 27, 1851-1854, 2000.

Huang, C.-S. and Hairston, M. R.: The postsunset vertical plasma drift and its effects on the generation of equatorial plasma bubbles observed by the C/NOFS satellite, J. Geophys. Res.-Space, 120, 2263-2275, doi:10.1002/2014JA020735, 2015.

Hysell, D. L. and Burcham, J. D.: JULIA radar studies of equatorial spread F, J. Geophys. Res., 103, 29115-29167, 1998.

Hysell, D. L. and Kudeki, E.: Collisional shear instability in the equatorial $F$ region ionosphere, J. Geophy. Res., 109, A11301, doi:10.1029/2004JA010636, 2004.

Hysell, D. L., Hedden, R. B., Chau, J. L., Galindo, F. R., Roddy, P. A., and Pfaff, R. F.: Comparing F region ionospheric irregularity observations from C/NOFS and Jicamarca, Geophys. Res. Lett, 36, doi:10.1029/2009GL038983, 2009.

Kherani, E. A., Abdu, M. A., de Paula, E. R., Fritts, D. C., Sobral, J. H. A., and de Meneses Jr., F. C.: The impact of gravity waves rising from convection in the lower atmosphere on the generation and nonlinear evolution of equatorial bubble, Ann. Geophys., 27, 1657-1668, doi:10.5194/angeo-27-1657-2009, 2009.

Kil, H. and Heelis, R. A.: Global distribution of density irregularities in the equatorial ionosphere, J. Geophys. Res., 103, 407-417, 1998.

Kil, H., Oh, S.-J., Paxton, L. J., and Fang, T.-W.: High-resolution vertical $\mathrm{E} \times \mathrm{B}$ drift model derived from ROCSAT-1 data, J. Geophys. Res., 114, A10314, 2009.

Kintner, P. M., Ldevina, B. M., and de Paula, E. R.: GPS and ionospheric scintillations, Space Weather, 5, S09003, doi:10.1029/2006SW000260, 2007.

Krall, J., Huba, J. D., Ossakow, S. L., and Joyce, G.: Why do equatorial ionospheric bubbles stop rising?, Geophys. Res. Lett., 37, 1944-8007, doi:10.1029/2010GL043128, 109105, 2010.

Kudeki, E., Fejer, B. G., Farley, D. T., and Ierkic, H. M.: Interferometer studies of equatorial $\mathrm{F}$ region irregularities and drifts, Geophys. Res. Lett., 8, 377-380, 1981.

Kudeki, E., Akgiray, A., Milla, M., Chau, J. L., and Hysell, D. L.: Equatorial spread $F$ initiation: Post-sunset vortex thermospheric winds, gravity waves, J. Atmos. Sol.-Terr. Phy., 69, 2416-2427, 2007.

Nishioka, M., Otsuka, Y., Shiokawa, K., Tsugawa, T., Effendy, Supnithi, P., Nagatsuma, T., and Murata, K. T.: On postmidnight field-aligned irregularities observed with a $30.8-\mathrm{MHz}$ radar at a low latitude: Comparison withF-layer altitude near the geomagnetic equator, J. Geophys. Res.-Space, 117, a08337, doi:10.1029/2012JA017692, 2012. 
Retterer, J. and Gentile, L. C.: Modeling the climatology of equatorial plasma bubbles observed by DMSP, Radio Sci., 44, RS0A31, doi:10.1029/2008RS004057, 2009.

Rodrigues, F. S., de Paula, E. R., Abdu, M. A., Jardim, A. C., Iyer, K. N., Kintner, P. M., and Hysell, D. L.: Equatorial spread F irregularity characteristics over Sao Luis, Brazil, using VHF radar and GPS scintillation techniques, Radio Sci., 39, RS1S31, doi:10.1029/2002RS002826, 2004.

Rodrigues, F. S., Hysell, D. L., and de Paula, E. R.: Coherent backscatter radar imaging in Brazil: large-scale waves in the bottomside F-region at the onset of equatorial spread F, Ann. Geophys., 26, 3355-3364, doi:10.5194/angeo-26-3355-2008, 2008.

Rodrigues, F. S., de Paula, E. R., and Chau, J. L.: On the characteristics of 150-km echoes observed in the Brazilian longitude sector by the $30 \mathrm{MHz}$ São Luís radar, Ann. Geophys., 29, 1905-1916, doi:10.5194/angeo-29-1905-2011, 2011.

Saito, S., Fukao, S., Yamamoto, M., Otsuka, Y., and Maruyama, T.: Decay of 3-m-scale ionospheric irregularities associated with a plasma bubble observed with the Equatorial Atmosphere Radar, J. Geophys. Res., 113, A11318, doi:10.1029/2008JA013118, 1998.

Scherliess, L. and Fejer, B. G.: Radar and satellite global equatorial F region vertical drift model, J. Geophys. Res., 104, 6829-6842, 1999.

Shume, E. B., de Paula, E. R., Kherani, E. A., Abdu, M. A., and Denardini, C. M.: Equatorial electrojet plasma irregularities observed during late afternoon by the $30 \mathrm{MHz}$ coherent scatter radar in Sao Luis, Brazil, J. Atmos. Sol.-Terr. Phy., 73, 1560-1567, 2011.

Sobral, J. H. A., Abdu, M. A., Takahashi, H., Taylor, M. J., and de Paula, E. R.: Ionospheric plasma bubble climatology over Brazil based on 22 years (1977-1998) of $630 \mathrm{~nm}$ airglow observations, J. Atmos. Sol.-Terr. Phy., 64, 1517-1524, 2002.
Stoneback, R. A., Heelis, R. A., Burrell, A. G., Coley, W. R., Fejer, B. G., and Pacheco, E.: Observations of quiet time vertical ion drift in the equatorial ionosphere during the solar minimum period of 2009, J. Geophys. Res., 116, A12327, doi:10.1029/2011JA016712, 2011.

Su, S.-Y., Chao, C. K., and Liu, C. H.: On monthly/seasonal/longitudinal variations of equatorial irregularity occurrences and their relationship with the postsunset vertical drift velocities, J. Geophys. Res., 113, A05307, doi:10.1029/2007JA012809, 2008.

Sultan, P. J.: Linear theory and modeling of the Rayleigh-Taylor instability leading to the occurrence of equatorial spread F, J. Geophys. Res.-Space, 101, 26875-26891, doi:10.1029/96JA00682, 1996.

Tsunoda, R. T.: On equatorial spread F: Establishing a seeding hypothesis, J. Geophys. Res.-Space, 115, a12303, doi:10.1029/2010JA015564, 2010.

Woodman, R. F.: Spread F - an old equatorial aeronomy problem finally resolved?, Ann. Geophys., 27, 1915-1934, doi:10.5194/angeo-27-1915-2009, 2009.

Woodman, R. F. and LaHoz, C.: Radar observations of F-region irregularities, J. Geophys. Res., 81, 5447-5466, 1976.

Yokoyama, T., Yamamoto, M., Otsuka, Y., Nishioka, M., Tsugawa, T., Watanabe, S., and Pfaff, R. F.: On postmidnight low-latitude ionospheric irregularities during solar minimum: 1. Equatorial Atmosphere Radar and GPS-TEC observations in Indonesia, J. Geophys. Res., 116, A11325, doi:10.1029/2011JA016797, 2011. 